\title{
Temas emergentes da etnomusicologia brasileira e seus compromissos sociais
}

\section{Angela Lühning}

(UFBA)

\begin{abstract}
Resumo: Este artigo centra-se nos os desafios recentes em etnomusicologia brasileira, analisando a trajetória histórica e representação geográfica da disciplina em relação à situação em alguns países do hemisfério norte. Esta situação atual da etnomusicologia brasileira explica questões como o seu compromisso social, a relação com as políticas públicas e proximidade com as discussões sobre educação e identidade cultural.
\end{abstract}

Palavras-chave: etnomusicologia, epistemologia, compromisso e sentido(s)

\section{EMERGING ISSUES OF BRAZILIAN ETHNOMUSICOLOGY AND ITS SOCIAL COMMITMENT}

Abstract: This article focuses about recent challenges in Brazilian ethnomusicology, analyzing the historical trajectory and geographic representation of the discipline compared to the situation in some countries in the northern Hemisphere. This current situation of Brazilian ethnomusicology explains issues such as her social commitment, the relationship with public policies and proximity with discussions on education and cultural identity.

Keywords: ethnomusicology, epistemology, commitment and sense(s) 


\section{Introdução}

Como discutir com estudantes interessados o que a etnomusicologia tem feito no Brasil e qual o seu papel social, de forma crítica e comprometida? O presente texto surgiu a partir desse desafio. Mas, apesar do título sugestivo, não se trata de uma reflexão sobre epistemologia, nem de uma discussão sobre possíveis procedimentos teóricos/ metodológicos na área da etnomusicologia e, tampouco, de uma análise de pesquisas recentes. Mas sim, trata-se de reflexões sobre questões de direcionamento de pesquisas na área de artes/humanas, com seus compromissos sociais decorrentes que chamaram minha atenção nos últimos anos. De certa forma também são reflexões sobre possibilidades e utopias, mas, levando em conta que utopias são frutos de necessidades reais, trata-se também de reflexões sobre realidades, mesmo que em vários planos temporais e espaciais.

Para entender a proposta desse texto é importante esclarecer a sua trajetória: ele é o produto final de duas versões de uma palestra que apresentei com poucos dias de distância temporal em encontros diferentes. A fala original, atendendo à sugestão temática dada pelos organizadores, foi apresentada no I Forum Norte Mineiro de Etnomusicologia em Montes Claros em meados de agosto para os alunos de graduação da UNIMONTES. Mas, em poucos dias ela teve de ser adaptada para transformar-se em uma conferência para ser apresentada na ANPPOM em João Pessoa no final de agosto de 2012. Tinha sido convidada para ficar no lugar de um colega da área de educação musical, impossibilitado de embarcar. O tema previsto da conferência, já anunciado, era voltado para a educação musical, o que me fez ampliar alguns aspectos da fala original para construir pontes entre etnomusicologia e educação musical, apesar de parecer, inicialmente, um desafio quase "sem sentido" (retomo isso no final do texto). A versão aqui apresentada é uma mescla das duas apresentações, embora mais focada na etnomusicologia, e se dirige, em especial, a pessoas que buscam completar suas leituras sobre a etnomusicologia brasileira.

O presente texto é dividido em três partes, além dessa introdução: uma primeira, mais geral, para pensar o lugar da etnomusicologia e da diversidade musical no Brasil, estabelecendo algumas comparações com outros países, em 
especial a Alemanha, ${ }^{1}$ uma segunda, mais específica, sobre os desafios emergentes, e uma terceira conclusiva.

Para poder falar de temas emergentes e compromissos sociais na etnomusicologia é preciso levar em conta lugares, não somente acadêmicos, mas também geopolíticos das áreas de conhecimento e suas sub-áreas, além da representatividade destes vários locais e das ações realizadas neles por pessoas. ${ }^{2}$ Quando apresentei a primeira versão desse texto na UNIMONTES em Montes Claros (MG) para alunos da graduação, percebi o grande interesse que lá existe na etnomusicologia, ao ponto de ter impulsionado nos últimos anos a trajetória de vários monteclarenses que hoje estão atuando em diversas universidades, especialmente em estados do Nordeste (PB, RN e CE). Mas, estes lugares são ainda recentes no mapa "geo-acadêmico" da pesquisa/atuação em etnomusicologia (e educação musical), fora do centro geográfico e geopolítico da produção acadêmica, assim como Montes Claros ou outras cidades de médio porte pelo Brasil adentro. Assim, ao tratar do tema proposto, estamos falando também das periferias geográficas da pesquisa em música no cenário acadêmico brasileiro, o que se estende aos temas abordados por elas em suas pesquisas e atuações de formação, em geral, dialogando com temas, necessidades e desafios novos.

Pode até parecer estranho pontuar a presença da etnomusicologia em Montes Claros, Sobral ou outras cidades como Pelotas ou Curitiba, ${ }^{3}$ por exemplo, mas a razão é simples: fica perceptível que não há somente uma expansão das

\footnotetext{
${ }^{1}$ A ênfase maior do texto está sendo colocada na trajetória da etnomusicologia nos países europeus, em específico a Alemanha, por ser um contexto ainda menos discutido do que o contexto dos EUA.

${ }^{2}$ Falo a partir da minha experiência como professora em uma universidade nordestina, a UFBA, que no seu Programa de Pós-Graduação em Música, iniciou em 1990 o primeiro mestrado com concentração em etnomusicologia no Brasil, e formou os mencionados docentes, hoje atuantes em universidades nordestinas (e outras), na área da etnomusicologia e afins.

${ }^{3}$ Montes Claros figura aqui apenas como exemplo pelo constante processo de interiorização não somente das universidades, mas também da etnomusicologia, pois pessoas formadas nessa área estão atuando como professores em Natal, Sobral, Crato, Feira de Santana entre outras universidades. Em algumas delas a etnomusicologia existe como área própria, em outras, por enquanto, apenas a presença de etnomusicólogos que estão contribuindo com novas visões de pesquisa e atuação na área de música. Podemos ampliar esse escopo para outros estados brasileiros que passam por experiências parecidas.
} 
universidades públicas pelo Brasil, mas também que a etnomusicologia está conquistando novos espaços que estão impulsionando novas reflexões. Isso não surpreende, se comparamos a situação da etnomusicologia brasileira com aquela dos países que deram início a esta disciplina, como veremos em seguida.

O surgimento e a trajetória da etnomusicologia envolve certo grau de "rivalidade" em relação aos "mitos de origem" da disciplina, em especial entre os Estados Unidos e a Alemanha, cada um destes países reivindicando a primeira iniciativa pelo estudo da música nos contextos das diversidades culturais. Mas, independente desta questão, hoje o papel da disciplina nesses dois países é bem diferente dos tempos inicias, um pouco mais que 100 anos atrás. O período de 1900 até a segunda guerra mundial talvez represente o tempo áureo da disciplina na Alemanha e as décadas posteriores nos EUA. Os detalhes desta trajetória podem ser conferidos em publicações dedicadas especialmente a esta questão. ${ }^{4}$

\section{A etnomusicologia no mundo ocidental e no Brasil}

Na Alemanha a etnomusicologia entrou nas últimas décadas do séc. XX em um período de retração, tendo sido absorvida em parte pela musicologia, além de ter buscado também novas aproximações à sociologia da música ou à educação musical, delineando novos caminhos no séc. XXI. Já nos EUA, apesar dela estar presente em muitas universidades e muitos cursos como uma das disciplinas de tronco comum, existem apenas poucas universidades nas quais há uma ênfase na etnomusicologia como área principal. Em ambos os países a etnomusicologia optou por caminhos e posicionamentos, cuja análise talvez possa explicar o mencionado fenômeno de retração.

Desde o tempo de seu surgimento, como musicologia comparada, depois como etnomusicologia, por muito tempo o foco principal da disciplina tem sido a pesquisa dos universos musicais fora dos respectivos países "proponentes" e da sua própria cultura. Isso não tem sido diferente na França e na Áustria, dois outros

\footnotetext{
${ }^{4}$ Ver o verbete "ethnomusicology" do New Grove Dictionary, (PEGG et allii, 2001) que não aborda a existência da etnomusicologia no Brasil ou na América do Sul.
} 
países que contaram desde 1900 com arquivos de fonograma, digamos, museus dos sons do mundo, onde as gravações realizadas em outras culturas ficaram armazenadas e encontram-se guardadas até hoje. ${ }^{5}$

Isso significa, por outro lado, que as culturas musicais dos países que "produziram" 6 os primeiros pesquisadores dificilmente foram abordadas por eles, a não ser a partir do olhar dos estudiosos do folclore inglês, da Volkskunde alemã ou então da etnologia. Assim, as respectivas culturas locais "autóctones" muitas vezes foram entendidas como menos importantes do que a própria música erudita europeia ou as músicas vistas como "exóticas", vindo do além-mar. Esse quadro trouxe consequências para as definições de música, cultura e identidade das culturas europeias. Como uma das exceções devem ser citadas as pesquisas realizadas pelos húngaros Bela Bartók e Zoltan Kodaly que ambos, já na sua época, representavam a periferia geográfica do cenário europeu. ${ }^{7}$

Mesmo que essa situação tenha sido revista de forma crítica através de estudos pós-coloniais, ela ainda representa em um dilema atual: até hoje um número grande de etnomusicólogos nos países ocidentais mencionados trabalha com culturas musicais geograficamente distantes, em geral situadas em outros continentes, o que reduz bastante a visibilidade destas pesquisas dentro dos países de origem dos pesquisadores. ${ }^{8}$ Assim, a etnomusicologia, de certo modo, virou uma área de especialistas que representam outras culturas, mas não criaram

\footnotetext{
${ }^{5}$ Ainda existem poucas propostas de políticas de repatriação de peças de museus ou de inserção de materiais históricos gravados e guardados em museus de som nas culturas de origem, pelos mais diversos problemas associados. Esse tema foi abordado em parte por uma publicação do Museu de Berlin (Berlin/Simon, 2002; ver também publicações e materiais disponíveis em https://katalogshop-smb.museumsportal.org/ museumsgebaude/ ethnologisches-museum.html). Apenas uma parte destes materiais tem sido digitalizada e publicada nos últimos anos, e menos ainda disponibilizada nos países de origem da gravação. A maior parte destes materiais nunca passou por uma "repatriação cultural". (ver os artigos de Seeger, Feld e outros autores na referida publicação).

${ }^{6}$ Usei o termo "produzir" de forma proposital, porque no período inicial da musicologia comparada/ etnomusicologia ainda não existia a possibilidade de formação no sentido atual.

${ }^{7}$ A atuação de Bartók como pesquisador musical foi analisada detidamente em analogia com a atuação de Mario de Andrade pelo livro de Elizabete Travassos (1999)

8 Além disso, é pouco comum existirem publicações resultantes destas pesquisas, feitas além-mar, nos países hospedeiros e suas instituições, e menos ainda resultados pensados para e com os participantes envolvidos nas pesquisas.
} 
diálogos entre estas culturas pesquisadas, distantes, e as próprias culturas de seus respectivos países. Mas, as consequências dos processos de descolonização e a pauta das reflexões sobre a situação pós-colonial também permearam este universo e surgiram novos centros acadêmicos voltados para o universo etnomusicológico mais sensíveis às novas demandas. Mesmo assim, ainda trata-se de uma parcela menor, mas crescente, de etnomusicólogos que dialoga com os desafios da inegável diversidade cultural, presente na Europa nas últimas décadas, após as profundas transformações políticas originadas pela queda do Muro de Berlim e a criação da União Europeia (EU) que trouxe fluxos consideráveis de imigrantes com suas vivências culturais para a região.

Na Alemanha há agora reflexões sobre as novas demandas da disciplina, de questões como educação multicultural (Vogels, 2013) a análises do futuro do público consumidor de concertos de música erudita (Neuhoff, 2008). Há também acaloradas discussões sobre novas demandas da disciplina e esforços em redefinila como musicologia cultural (Greve, 2002, Klenke et Allii, 2003), além de criar novas nomenclaturas (Göttingen e Weimar) ${ }^{9}$ ou a inserção em redes europeias de pesquisa. Estas propostas de redefinição e reconhecimento de novos contextos em resposta às profundas mudanças da sociedade parecem estar em caminho promissor, diferente de situações anteriores, nas quais um certo engessamento da área no cenário universitário tinha levado a cortes de vagas de professores e, com isso, também à redução de vagas para estudantes. ${ }^{10}$ Assim, naquele país, a grande área da musicologia está discutindo as suas responsabilidades, limites e identidades, questões discutidas por Greve (2001).

9 Favor consultar as páginas dos respectivos institutos de (etno)musicologia: $<$ http://www.uni-goettingen.de/de/wir-ueber-uns/355775.html e https://www. hfmweimar.de/651/\#HfM>.

${ }^{10}$ Em casos extremos ocorreu até o fechamento de institutos autônomos, hoje integrados em outros, conceitualmente próximos, como a musicologia histórica ou a musicologia sistemática. A lista de todos os institutos de musicologia em países de língua alemã encontram-se no site da maior revista da área "Die Musikforschung", informando detalhes das estruturas de cada um dos cursos oferecidos: <ttp://www.musikforschung.de/ index.php/studium-musikwissenschaft\#G>. 
Todos estes fatores parecem explicar uma posição relativamente "marginal" da etnomusicologia na Alemanha e nos outros países europeus mencionados nas décadas anteriores a 2000, quando havia ainda poucos vínculos mais profundos e cotidianos com as sociedades civis ao seu redor. São sociedades complexas que lidam hoje com música de múltiplas formas e origens, que vão muito além do fazer acústico e da relação direta da produção sonora com as pessoas, mas incluem também os mais diversos processos midiáticos e tecnológicos. Já as mudanças de ação apontadas são recentes e coincidem também com o período de uma guinada da disciplina no Brasil.

Aparentemente pode parecer que não há nenhuma ligação desse cenário, apresentado de forma muito resumida, com o Brasil. Mas, ao contrário, acredito que ele permite fomentar as análises do cenário brasileiro, no mínimo, para perceber várias diferenças, mas também algumas semelhanças. Pois, diferente do cenário europeu, o constante crescimento da área de etnomusicologia no Brasil não passou por uma fase de "adormecimento", ao contrário, ela começou a construir logo seu caminho próprio.

A etnomusicologia instalou-se como área disciplinar no Brasil primeiro em nível de pós-graduação, em 1990 na UFBA, embora nos anos 80 já tenha ocorrida a formação de vários dos profissionais hoje atuantes ainda fora do Brasil, devido à ausência de um curso de formação específica. Além disso, teve aqueles que inicialmente ficaram no Brasil e trabalharam questões etnomusicológicas a partir de outras áreas acadêmicas, especialmente a antropologia. ${ }^{11}$ Desde 1990 a etnomusicologia acabou propondo algo diferente do que vimos na Europa e nos EUA, assumindo o papel de uma área que dialoga com as expressões de música a partir da reflexão sobre práticas musicais brasileiras em busca dos seus conceitos próprios. Isso tem gerado, inicialmente, até críticas de colegas de ofício, definindo a etnomusicologia brasileira como descritiva (Béhague, 1999), porém, subestimando o gradual desenvolvimento de seu potencial crítico e político.

11 Sandroni (2008) analisa as trajetórias dos etnomusicólogos atuantes no Brasil, especialmente aqueles da "primeira" geração com suas formações ainda fora do país e suas atuações em programas de música e de antropologia. Ver sobre o tema também uma primeira abordagem de Lühning (1991). 
É importante lembrar que até então, salve engano, em todas as escolas de música do país, incluindo aqui os conservatórios, o ensino e o estudo da música era voltado apenas para o repertório da música erudita europeia, ou então, no máximo da abertura, à música erudita brasileira. Já a complexidade das demais tradições e expressões musicais do país ou era tratada apenas como folclore ou música de cunho comercial ou, então, simplesmente não percebida como merecedora de uma reflexão maior. Prova disso é que até os cursos de música popular brasileira ainda são muito recentes no contexto universitário brasileiro, tendo surgido apenas há poucos anos.

Com a inserção da etnomusicologia no cenário universitário este quadro de percepção (de)limitada de música começou a mudar aos poucos e finalmente surgiu uma proposta conceitual que permitisse perceber e discutir a diversidade das tradições musicais brasileiras a partir de outro ângulo. Esse período coincidiu com a implantação de políticas públicas específicas, tanto da parte da UNESCO quanto do Ministério da Cultura, dando visibilidade a mestres e mestras, protagonistas das expressões musicais e, finalmente do projeto Encontro de Saberes (INCTI/MINC), idealizado por José Jorge de Carvalho. ${ }^{12}$

A etnomusicologia permitiu que se construísse aos poucos uma visão diferente de música, certamente influenciada pela sua proximidade conceitual e metodológica com a antropologia. Assim, construiu-se no cenário brasileiro uma situação diferente dos países mencionados anteriormente: a etnomusicologia brasileira dialoga desde o início idealmente com as demandas da sociedade contemporânea (depois explico por que uso o termo idealmente) e aceita desafios

\footnotetext{
12 Ainda há opiniões que creditam a atenção dada às tradições musicais brasileiras aos estudos do folclore, vistos como precursores ou até, como idênticos aos temas abordados pela etnomusicologia. Mas, discordo disso por uma questão simples: os folcloristas se interessavam apenas pelo assim chamado "fato folclórico". Centro de sua atenção eram as manifestações em si, com suas estruturas internas, sem se interessarem pelas interrelações destas manifestações com as pessoas e a sociedade, deixando de incluir nas análises aspectos sociais, políticos e históricos, enfim, uma discussão da função social da música e sua iminente força simbólica e política. Assim, ocorreu uma reificação de tradições culturais pelos estudos folclóricos (e, assim, do conceito da diversidade cultural brasileira), vendo-as com uma percepção bastante estática, em vez de entendê-las como criativas e dinâmicas em constante processo de transformação. O projeto Encontro de Saberes é um bom exemplo para essa nova visão.
} 
em relação à análise e compreensão de contextos culturais socialmente e geograficamente complexos nas suas diferenças e até contradições. O que é bem presente nos estudos etnomusicológicos brasileiros são também os diálogos com outras áreas ao seu redor, da história à tecnologia, incluindo a área de educação musical como interlocutora. É esta visão mais ampla da área que também traz os desafios atuais que gostaria de pontuar na segunda parte deste texto.

\section{Os desafios atuais, seus enredos e as pontes}

Podemos perguntar quais são os temas abordados nos trabalhos desenvolvidos nestes quase 25 anos da inserção acadêmica da etnomusicologia no Brasil e quais os possíveis desdobramentos? Para entender a cena atual a partir das mudanças ocorridas nesse período, em especial em relação ao foco e à abrangência dos estudos realizados, cito, a título de exemplo, as mais que 60 dissertações e teses de etnomusicologia já defendidas no PPGMUS da UFBA até o presente momento, além de outros textos que surgiram como desdobramentos desses trabalhos acadêmicos. ${ }^{13}$ Inicialmente tratava-se mais de etnografias e estudos de caso relativos a contextos musicais bastante específicos, estudando comunidades indígenas, comunidades religiosas afrobrasileiras, tradições musicais de grupos de imigrantes, rurais e urbanas. Já nos últimos anos aqueles trabalhos que tem buscado um diálogo ainda mais direto com os protagonistas dos contextos musicais têm aumentado, mesmo que muitas das pesquisas mencionadas já eram realizadas em comunidades e contextos próximos às vivências culturais dos pesquisadores. Aos poucos este quadro foi se ampliando e

\footnotetext{
${ }^{13}$ Gostaria de apresentar dados mais abrangentes, para poder avaliar as possíveis mudanças conceituais em relação a temas ou abordagens empregadas, mas ainda não há números precisos sobre o total de trabalhos acadêmicos realizados na área de etnomusicologia nas duas últimas décadas. Infelizmente os dados presentes no banco de dados da CAPES ainda são incompletos, o que impossibilita uma análise quantitativa e qualitativa sobre as questões mencionadas acima. Apenas um levantamento detalhado em cada um dos programas de pós-graduação no Brasil com área de concentração em etnomusicologia permitiria este levantamento das prováveis mudanças como expressão de novas propostas conceituais. Por isso, minhas observações se fundamentam nos trabalhos desenvolvidos na UFBA, bem como na observação de apresentações de trabalhos em livros, congressos e bancas.
} 
começou-se a questionar a autoridade e representatividade do pesquisador e com isso a real relevância das pesquisas acadêmicas para as comunidades envolvidas, buscando novas possibilidades de interlocução, representação, participação e colaboração.

De um lado isso pode ser interpretado como um momento de crise da etnomusicologia (Laborde, 2008) bem como de outras áreas das ciências humanas que começaram a se sentir questionadas pelas exigências de outros segmentos sociais, que finalmente se colocaram de forma mais crítica em relação a autoridade etnográfica e a participação não questionada das comunidades em pesquisas (Barz/Cooley, 1997, e Fonseca, 2004). Novamente é necessário lembrar a trajetória histórica da pesquisa sobre as músicas brasileiras, consideradas folclóricas ou até "exóticas": no início da existência da disciplina tratava-se em geral de pesquisas realizadas por pessoas estranhas aos contextos, muitas vezes por viajantes ou pesquisadores estrangeiros, sem que existisse algum tipo de relação posterior entre estes pesquisadores e os "pesquisados", termo muito comum até á segunda metade do séc. XX. Elas foram aos poucos substituídas pelas propostas ligadas ao conceito da pesquisa participante, ${ }^{14}$ embora muitas vezes realizando pesquisas apenas porque faziam parte das exigências acadêmicas. Porém, finalmente, parece que estamos em uma fase, na qual uma pesquisa não deve ser pensada ou realizada sem uma efetiva discussão de seu contexto e seus objetivos com aqueles sujeitos, diretamente envolvidos naquela pesquisa, o que traz a necessidade de pensar também em questões como responsabilidade social, ética e outros temas e fomentar efetivamente propostas colaborativas.

Quer dizer, idealmente existe hoje um cenário no Brasil em que a pesquisa etnomusicológica (e antropológica) passa por novas exigências e necessidades, não por último, devido às mudanças recentes, especialmente nos últimos 10 anos, na área de educação e, também na educação musical. Penso nas duas leis 10.639/03 e 11.645/08, prevendo o ensino da cultura afro-brasileira e indígena e o próprio ensino de música nas escolas, pela lei 11.769/08. Se antes não havia um lugar para a discussão de temáticas étnicas e de diversidade cultural,

\footnotetext{
${ }^{14}$ Lembro aqui de um dos primeiros livros abordando este conceito: Brandão (1981).
} 
hoje isso se tornou uma questão quase "indiscutível", apesar de tampouco ser uma questão unânime. Além disso, a real inserção desses temas no ensino escolar, que de fato poderia provocar uma gradual mudança nas percepções de cultura, ainda não ocorreu, por motivos diversos, dos quais mencionarei apenas alguns. ${ }^{15}$

Para trabalhar estas temáticas nas escolas hoje, certamente é necessário existir um acesso amplo a informações sólidas sobre a diversidade cultural, em geral, oriundas de publicações das ciências humanas, incluindo nelas aqui também a etnomusicologia. Em relação a estas publicações mais recentes acredito ter ocorrido um salto qualitativo, pois buscam sempre mais uma visão contextual, crítica, comprometida e, assim, política. Parcerias e diálogos com várias áreas de conhecimento ao redor da etnomusicologia como a advocacy antropology, (Haskell/Loughran, 2003) certamente tem contribuído para isso. Quem dialoga por sua vez com as novas posturas da etnomusicologia é a área da educação musical, mas também as instâncias que trabalham com políticas públicas. Especialmente a possibilidade de relações entre etnomusicologia e educação musical, a partir do interesse e da necessidade de trabalhar com a diversidade cultural brasileira, constitui um importante desafio.

Mesmo assim, há alguns questionamentos por grupos de pessoas em relação à abordagem destes temas nas escolas ou em outros ambientes, como p.ex. a cultura afro-brasileira e africana, em geral, por questões de ordem religiosa. Pois, é conhecido que há um grande número de pessoas que nos últimos anos aderiram a religiões evangélicas, muitas vezes instadas a negar os seus vínculos culturais anteriores. Isso é algo bastante comum em Salvador, onde existe, além de um número bem acentuado de população afro-descendente e manifestações culturais e religiosas afro-brasileiras, também um número sempre maior de evangélicos, em maior parte afro-descendentes, se comparado com a situação de 10 a 20 anos atrás, quadro que ocorre também em muitos outros lugares. Por isso, há hoje muitas pessoas em Salvador, inclusive muitos

\footnotetext{
${ }^{15}$ Uma das questões principais é a contínua redução das culturas africanas, afro-brasileiras e indígenas à noção de folclore, sem que haja uma abordagem mais profunda da questão. Essa associação data ainda do tempo da ditadura, responsável pela instituição do dia do folclore em 1965, ratificando assim os conceitos antagônicos de folclore e cultura, e impossibilitando qualquer discussão mais séria do tema.
} 
professores, que consideram como discutível a inserção destas temáticas, mesmo sendo previstas por lei, como uma medida de reparação histórica em relação ao assunto e as populações nele envolvidas. Quer dizer, existe no Brasil uma ideia amplamente difundida de que cultura seria sinônimo de religião, pois a presença da cultura africana para muitos tem se cristalizado em aspectos religiosos, sem perceber os demais aspectos culturais envolvidos e por isso, negando-se a abordar a temática das referidas leis. Essa situação requer certamente uma ampla discussão, além de um posicionamento engajado da parte de educadores musicais e etnomusicólogos (Lühning, 2013).

Por todos estes motivos mencionados, acredito que o estabelecimento da etnomusicologia no Brasil tenha sido trilhado por caminhos diferentes dos países europeus ou dos EUA, com isso não invalidando as iniciativas recentes que apresentem enfoques inovadores naqueles países. E isso nos permite chamá-la de etnomusicologia brasileira (Lühning, 2006), por perceber o seu grande potencial e papel social, o que não quer dizer que ela seja entendida assim por todos os seus representantes. Mas coloco isso, por acompanhar a atuação de vários colegas que entendem a etnomusicologia desta forma mais ampla e comprometida, como tendo afinal um papel iminentemente político que ela está assumindo, quanto mais ela sai das universidades dialogando com a sociedade. ${ }^{16}$

Mas quais seriam então os desafios atuais da etnomusicologia brasileira? Acredito que seja a continuação deste caminho que delineei, com temas sempre mais amplos na sua dimensão de questionamento, de contribuição para a discussão de temas que abordem a composição da sociedade brasileira, a inserção de segmentos sociais, identidades, questões de gênero, políticas educacionais e culturais, direitos coletivos de propriedade intelectual ou conhecimentos tradicionais e do uso de tecnologias. A lista pode ser quase infinita, mas acredito que o fundamental é a consciência do papel social e cultural da etnomusicologia no cenário de pesquisa e formação na área de humanas/ artes hoje existentes. E

\footnotetext{
${ }^{16}$ Entre vários outros menciono aqui em especial as atuações constantes dos colegas Samuel Araujo, Rosângela Tugny, Glaura Lucas, Luis Ricardo Queiroz, Marília Stein, Luciana Prass e Liliam Barros.
} 
por analogia gostaria de incluir desde já a educação musical nesse processo de reformulação de paradigmas.

Porém, em relação à escolha de temas de possíveis pesquisas há outra questão importante a ser considerada: pois, o maior desafio para mim não é um possível tema em si, mas a percepção da escolha devido à relevância para um grupo maior de pessoas. E nisso coloco os acadêmicos apenas entre diversos outros grupos, pois defendo que as relevâncias não devem ser definidas apenas a partir do olhar dos assim chamados parâmetros acadêmicos, mas também a partir daquele das pessoas envolvidos nas pesquisas (na área das humanas e artes), que de alguma forma também devem ser beneficiados pelas pesquisas. Isso representa uma mudança de paradigma, pois, seguindo esta lógica, não seria mais o ineditismo do ponto de vista acadêmico de um tema que o torna relevante, mas a sua necessidade política e até urgência social/ cultural que, pelo menos, devem ser cogitadas como aspectos importantes na delimitação dos possíveis temas.

Isso talvez possa soar radical, mas este caminho me parece mais aceitável do que a ideia de que o tema em si se justifica por ser bem elaborado, metodologicamente consistente, teoricamente ancorado, entre outros, apelando assim à chamada excelência acadêmica, que virou uma categoria quase à parte. Nesse sentido considero que os temas emergentes e relevantes são todos aqueles que apresentam este compromisso social, educacional, independente dos seus temas, digamos, mais especificamente acadêmicos em si. Menciono algumas questões para deixar mais claro o que quero dizer: temas emergentes são os temas que lidam com tradições ou expressões musicais em constante diálogo com as pessoas envolvidas nelas, o que pode ocorrer em contextos urbanos comunitários em situação de vulnerabilidade social, grupos minoritários, como grupos indígenas, quilombolas ou ribeirinhas, processos educacionais escolares ou não escolares, em contextos geográficos e sociais periféricos ou não, questões de transmissão e processamento de informações através dos mais diversos meios, novas formas e processos criativos, hoje tão relacionados com novas tecnologias e processos midiáticos, entre muitos outros possíveis temas.

Mas há mais um aspecto a ser considerado: algo muito importante neste processo é também a percepção da necessidade de criar, construir e desenvolver 
outros tipos de resultados, além das tão conhecidas monografias, dissertações ou teses, ou então os artigos, de preferência a serem publicados em revistas conceituadas, até em línguas estrangeiras. Não adianta pensar que a entrega de um exemplar da tese ao participante de uma pesquisa vai colaborar necessariamente para a circulação de conhecimento, "devolver" ou retribuir o que se construiu argumentativamente a partir das participações dos sujeitos sociais envolvidos. ${ }^{17}$ É necessário pensar também em textos com linguagens e em formatos acessíveis, outros materiais resultantes ou ações que de fato podem ser significativos para as pessoas envolvidas nas pesquisas e a sociedade em geral. Só assim os benefícios serão mais equilibrados entre as partes desta equação de forças que expressa sempre relações de poder e estruturas sociais assimétricas muito arraigadas.

Aqui incluo também os professores da educação básica, até hoje tão pouco reconhecidos, inclusive pelos professores universitários, que deveriam ter o direito de acesso a possibilidades de interlocução para sua formação continuada através de materiais de circulação ampla, ou melhor, materiais específicos para os contextos de sua atuação em relação às questões de cultura e artes. Penso aqui na construção de possibilidades, parecidas com aquilo que acontece no âmbito da educação diferenciada com professores indígenas que hoje finalmente podem trabalhar primeiro (na sua própria língua) os contextos culturais de seus respectivos grupos étnicos para depois entrarem em questões da cultura/ história do Brasil, incluindo o português.

Especialmente os professores das escolas públicas, atuando na área de música ou não, precisam de materiais fundamentados para trabalhar as questões das identidades locais e regionais, em vez de manter a ideia teórica de uma cultura nacional única que na prática nunca existiu. Estes materiais deveriam ser fruto da participação maciça dos pesquisadores na assim chamada divulgação científica como compromisso social e ético das universidades, mantidas com dinheiro público, materiais que não necessariamente precisam ser didáticos.

\footnotetext{
${ }^{17}$ Um dos textos mais importantes que abordou a problemática das relações entre carreiras acadêmicas e benefícios pessoais e coletivos foi o texto de Davis, 1995.
} 
No inicio mencionei que este texto não seria propriamente uma reflexão sobre procedimentos metodológicos ou teóricos, e de fato não mencionei nenhum deles até agora, mas por qual motivo? Por que acredito que, a partir das várias colocações anteriores, tenha ficado claro que a questão principal dessas reflexões é menos direcionada para questões de terminologia conceitual do que para reflexões sobre desdobramentos de análises e posicionamentos comprometidos e suas inserções em ações várias, assim guiando a atuação dos etnomusicólogos no Brasil.

As posturas de responsabilidade e comprometimento que coloquei nesta abordagem da etnomusicologia brasileira podem ser chamadas de etnomusicologia aplicada, participativa, dialógica, colaborativa ou então de empirismo radical, mesmo que estes aportes teóricos/ metodológicos possuam definições diferenciadas e possam ser percebidas ou defendidas como sendo diferentes entre si. ${ }^{18}$ Isso é apenas natural, pois todos eles sugiram em lugares geográficos e momentos temporais diferentes. Mas, o mais importante, a final, é uma atuação socialmente comprometida através de novos processos dialógicos, colaborativos, não importando muito o termo que se aplica, pois já temos muitos existentes.

\section{$O(s)$ sentido(s) da/na etnomusicologia}

Além disso, ainda há mais um aspecto que citei no início quando mencionei que queria "dar sentido" ao texto no momento de aceitar o convite para a segunda fala. Pois, na verdade, trata-se de uma questão bastante séria, apesar de sua vinculação com aspectos que poderíamos chamar de lúdicos. Explico: ao observar as expressões específicas da diversidade cultural/ musical brasileira, podemos perceber que todas elas estão sendo vividas pelas pessoas envolvidas com todos os seus sentidos, falando aqui de fato nas percepções sensoriais.

\footnotetext{
${ }^{18}$ Há uma ampla produção bibliográfica sobre cada um destes termos, seja em português ou em outras línguas, que pode ser consultada através de muitos textos disponíveis na internet.
} 
Nós, pesquisadores, ainda não percebemos isso de forma suficiente, pois, de fato existe um forte envolvimento sensorial em todos os contextos, que vai além da percepção do som físico-acústico. Esse espectro sonoro, a música e suas representações, colocamos durante muito tempo no centro de nossas atenções, preocupados com análises quantitativas, também para tornar as nossas produções cientificamente validadas. Assim, raramente percebemos os demais sentidos presentes nas práticas musicais, que envolvem, além do corporal/ kinético e tátil, perceptível em múltiplos movimentos, o visual/ cênico/ espacial e o olfato a partir de contextos que incluem cheiros, enfim, todos os estímulos diversos presentes em contextos que podem ir do lúdico ao ritualístico. Isso, sem mencionar a importância das intensas relações interpessoais, que permeiam essas experiências sensoriais, com seu poder de integração social, criando fortes noções de identificação e pertencimento que assim também conferem sentido às vivências artísticas e culturais. ${ }^{19}$

A compreensão desses vários sentidos de viver com e através de todos os sentidos parece-me um dos maiores desafios para todos que queiram entender estas complexas interrelações. Trata-se de mais do que uma mera questão de cunho estético ou estilístico, mas de uma necessidade conceitual urgente para começar a pensar também os possíveis caminhos para uma redução das incompreensões sociais, tão diretamente ligadas a concepções abstratas e até contraditórias entre si como arte, cultura, brincadeira, lazer e fruição.

Para as pessoas das próprias práticas culturais todos esses contextos multissensoriais "fazem sentido", usando esta expressão como metáfora, além de darem-Ihes prazer. Mas não "faz sentido" para elas aquilo que, em geral, se produz sobre elas ou os contextos culturais vividos por elas. Neste sentido nós, pesquisadores, precisamos "dar sentido" às nossas ações de diálogo com contextos de pesquisa e de inserção de resultados em ações culturais, pedagógicas ou não. Precisamos incluir a análise das amplas questões sociais e políticas nas nossas percepções e, assim, também repensar o papel do próprio campo acadêmico, em

19 Recomendo assistir ao filme "Tarja Branca - a revolução que faltava", filme documentário de Cacau Rhoden, lançado em 2014 que aborda todas estas questões ligadas à criatividade e ludicidade de forma muito lúcida. 
última instância envolvendo até a CAPES e outras agências de fomento e avaliação com suas exigências. Pois, a produção comprometida que deveria "fazer sentido" para as pessoas envolvidas e também para a sociedade, produzindo diversos materiais e ações de circulação do conhecimento (comumente chamada de divulgação científica), com possibilidades de inserção pedagógica, também deveria valer tanto quanto aquela das revistas renomadas de circulação restrita. Cabe a nós mesmos convencer a CAPES e seus representantes, que são os nossos pares, dessa necessidade, se assim o desejamos de verdade.

Gostaria de concluir dizendo que seja possível que tudo o que foi discutido até agora, ressaltando, em especial, a questão do engajamento e a necessidade da mudança de foco na definição e realização das pesquisas emergentes na etnomusicologia brasileira, seja apenas uma ilusão minha. E, se, por acaso, for isso mesmo, espero que a minha visão do potencial da etnomusicologia e, em analogia, também da educação musical comprometida, de fato se torne uma realidade na prática da pesquisa do país e sua inserção nos mais diversos contextos sociais. Mas, desde já ressalto que a inserção destas primeiras ações e discussões da etnomusicologia brasileira na sociedade brasileira, apesar de seu pouco tempo se presença, parece ser muito mais forte do que ela já foi ou possa ter sido nos países europeus em momentos anteriores da trajetória histórica da disciplina.

E assim a minha possível ilusão vira utopia e vai mais longe ainda: acredito que seja possível que, em um futuro talvez não tão distante, esta nova postura da etnomusicológia brasileira (que já alimenta várias pesquisas da área e, em analogia, também atuações da educação musical), com base nas suas experiências de inserção na sociedade brasileira possa "retornar" à Europa com esta nova visão, diferente daquela que saiu de lá algumas décadas atrás. Esta etnomusicologia socialmente comprometida e inserida no dia-a-dia de uma sociedade que a abarca, abraçando-a, também poderia atuar em uma Europa hoje etnicamente tão diversificada, às vezes até dividida, muito diferente daquela existente quando a etnomusicologia foi criada. Assim, a etnomusicologia também poderia "fazer sentido" para todos os envolvidos na vivência e no estudo das práticas culturais atuais na Europa. 


\section{Post-scriptum}

Mas, ainda existe uma incógnita ao final da reflexão utópica sobre uma possível "migração" da etnomusicologia brasileira para o hemisfério norte: a disciplina continuaria com o seu atual nome ou não? Isso certamente ainda é outra questão, que vai muito além dos temas discutidos aqui. Mas, pensando bem, talvez ela nem tenha importância diante do tamanho, da importância e da urgência das outras questões antes abordadas no decorrer do texto.

\section{Referências}

BARZ, Gregory F.; COOLEY, Timothy J. (eds.). Shadows in the Field: New Perspectives for Fieldwork in Ethnomusicology. New York and Oxford: Oxford University Press, 1997.

BEHAGUE, Gerard. "A etnomusicologia latino-americana: algumas reflexões sobre sua ideologia, história, contribuições e problemática." Anais do $2^{\circ}$ Simpósio Latino-Americano de Musicologia. 1999, p. 41-69.

BRANDÃO, Carlos Rodrigues (org.) . Pesquisa participante. São Paulo, Brasiliense, 1981.

DAVIS, Martha Ellen: "Carreers and "alternative" carreers in the unity bnetween theory and practice in ethnomusicology. "In: Ethnomusicology, vol.36/3, 1992, p. 361-387.

FONSECA, Claudia. “Antropólogos para que? O Campo de atuação profissional na virada do milênio”. In: TRAJANO FILHO, Wilson/ RIBEIRO, Gustavo Lins (Orgs.). O campo da antropologia no Brasil. Rio de Janeiro: Contra Capa Livraria/ Associação Brasileira de Antropologia, 2004, p. 69-92.

GREVE, Martin. "Writing against Europe. Vom notwendigen Verschwinden der, Musikethnologie“. Die Musikforschung, 55 (3), 2002, p. 239-251.

HASKELL, Erica/ LOUGHRAN, Maureen. Invested in Community . Ethnomusicology \& Musical Advocacy. Brown University, 2003.

KLENKE, Kerstin, KOCH, Lars-Christian, MENDIVIL, Julio, Rüdiger Schumacher, SEIBT, Oliver, VOGELS, Raimund. "Totgesagte leben länger - Überlegungen zur Relevanz der Musikethnologie“. Die Musikforschung, 56 (3), 2003, p. 261-271.

LABORDE, Denis. "A etnomusicologia serve ainda para alguma coisa”. Música em contexto. Brasília, n. 1, 2008, p. 27-46.

LUHNING, Angela. "Etnomusicologia Brasileira como Etnomusicologia participativa: Inquietudes em relação às musicas brasileiras”. In: Músicas Africanas 
e indígenas no Brasil. TUGNY, Rosangela P. de /QUEIROZ, Ruben C. de (org.). Belo Horizonte: Editora UFMG, 2006, p. 37-55.

. "Na encruzilhada dos saberes e fazeres musicais: conhecimentos tradicionais, educacao, musica e espaco(s)". In: Transito entre fronteiras na música. (BRAGA, Lia; TOURINHO, Cristina; ROBATTO, Lucas, org.), PPGArtes/ UFPA, Belém, 2013, p. $11-54$.

- "Métodos de Trabalho na Etnomusicologia: Reflexões à volta de experiências pessoais". Revista Brasileira de Ciências Sociais, Fortaleza, v. 22, p. 105-126, 1991.

NEUHOFF, Hans, Konzertpublika, Sozialstruktur, Mentalitäten, Geschmacksprofile, MIZ Bonn, [2008?,. s/d] in: http://www.miz.org/static_de/ themenportale/ einfuehrungstexte_pdf/03_KonzerteMusiktheater/neuhoff.pdf. Acessado em 10/ $8 / 2012$

PEGG, Carole; MYERS, Helen; BOHLMAN, Philip, STOCKES, Martin. "Ethnomusicology". IN: The New Grove Dictionary of Music and Musicians. $2^{\text {nd }}$ Ed. Oxford: Oxford University Press, 2001.

SANDRONI, Carlos. "Apontamentos sobre a história e perfil institucional da etnomusicologia no Brasil”. REVISTA USP, São Paulo, n.77, p. 66-75, março/maio 2008.

TRAVASSOS, Elizabeth. Os Mandarins Milagrosos: Arte e Etnografia em Mário de Andrade e Béla Bartók. Rio de Janeiro: Ministério da Cultura /Funarte/Jorge Zahar Editor, 1997.

VOGELS, Raimund . "Identität und Diversität in der Musikethnologie". In: Beyond Borders: Welt - Musik- Pädagogik. Musikpädagogik und Ethnomusikologie im Diskurs. ALGE, Barbara/ KRÄMER, Oliver (orgs.) Wissner-Verlag, Augsburg 2013. p.81-92.

ZIEGLER, Susanne. Die Wachszylinder des Berliner Phonogramm Archivs. Staatliche Musen zu Berlin, 2006. 